\title{
Study on the difference of pore structure characteristics between the main oil reservoir and the second oil reservoir in Daqing Oilfield
}

\author{
Hongda Teng* \\ Research Institute of Exploration and Development of Daqing Oilfield Company Ltd., Heilongjiang Daqing, China.
}

\begin{abstract}
In order to study the difference of pore structure characteristics between the second oil reservoir and the main oil reservoir in Daqing oilfield, the pore structure characteristic parameters of core were characterized by routine mercury injection experiment. The results show that the average pore radius of the main reservoir ranges from $5.24 \mu \mathrm{m}$ to $12.50 \mu \mathrm{m}$, the sorting coefficient ranges from 1.14 to 3.08 , the median saturation pressure ranges from $0.04 \mathrm{MPa}$ to $0.27 \mathrm{MPa}$, and the maximum median radius can reach $15 \mu \mathrm{m}$. The permeability is high and the displacement pressure is low. The average pore radius of the second type reservoir is in $2.21 \mu \mathrm{m} \sim 9.03 \mu \mathrm{m}$, the sorting coefficient is $2.70 \sim 4.77$, the median saturation pressure is $0.076 \mathrm{MPa} \sim 5.148 \mathrm{MPa}$, the maximum radius is only $5 \mu \mathrm{m}$, and the permeability is low and the displacement pressure is high. It is important to clarify the difference of reservoir pore structure characteristics for efficient reservoir development.
\end{abstract}

\section{Introduction}

Pore structure of reservoir rock is characterized by influencing reservoir fluid reservoir capacity and oil and gas resources are the main factors, especially the multiphase fluid in the reservoir seepage features, in addition to its place of temperature and pressure conditions and the interaction between rock and fluid (wetting, adsorption, etc.), more important is related to the microscopic pore structure characteristics of the reservoir. Clear, therefore, the reservoir pore radius, the radius of the median, sorting coefficient and permeability, expulsion pressure 2 kinds of microscopic pore structure characteristics of the reservoir rock and its distribution, is to increase the crude oil recovery factor and the key to reservoir development effect, to the sustainable development of oil field implementation, eventually improve the economic benefits of oilfield has very important practical significance[1-3].

\section{Routine \\ mercury \\ injection experiment}

A total of 398 rock samples from 19 Wells in the second and main oil reservoirs of daqing placanticline were selected for routine mercury injection experiments, of which 231 are the main oil reservoirs and 127 are the second oil reservoirs. The main oil layer is putaohua oil layer and the second oil layer is Saertu oil layer. These cores were subjected to conventional mercury injection to collect pore structure characteristic parameters.

\subsection{Characteristic analysis of core capillary pressure curve}

Capillary pressure curve of rock samples comprehensively reflects pore size and connectivity controlled by larynx. Morphological characteristics of capillary pressure indicate different pore structures of samples. Is closely related to the permeability of capillary pressure curve, as the permeability from large to small, capillary pressure curve from lower left direction on successive arrangement, the greater the permeability, capillary pressure curve, the convex to the lower left corner, and the horizontal axis parallel flat long, shows that the micro pore structure is good, throat size, the greater the uniform pore throat, the lower the expulsion pressure[4]. On the contrary, for the sample with low permeability, the capillary pressure curve is far away from the horizontal axis. The farther away from the horizontal axis, the flat segment gradually decreases, and the worse the microscopic pore structure is, the lower the permeability is, and the higher the displacement pressure is. The length of gentle section indicates that the laryngeal radius is large and the proportion of the large laryngeal radius is large.

Figure 1 shows the capillary pressure curves of the main and secondary oil zones in two Wells. It can be seen that the capillary pressure curve of the main oil reservoir is close to the lower left, and there is a gentle section, indicating that the main oil reservoir has high permeability, large pore radius, a large proportion of large pores, good pore throat sorting, and low capillary pressure[5]. The capillary pressure curve of the second

\footnotetext{
* Corresponding author: 523411995@qq.com
} 
type oil reservoir is far away from the horizontal axis. Compared with the main oil reservoir, the flat section is smaller, the permeability is lower, the pore-throat sorting is not good, and the displacement pressure is higher.

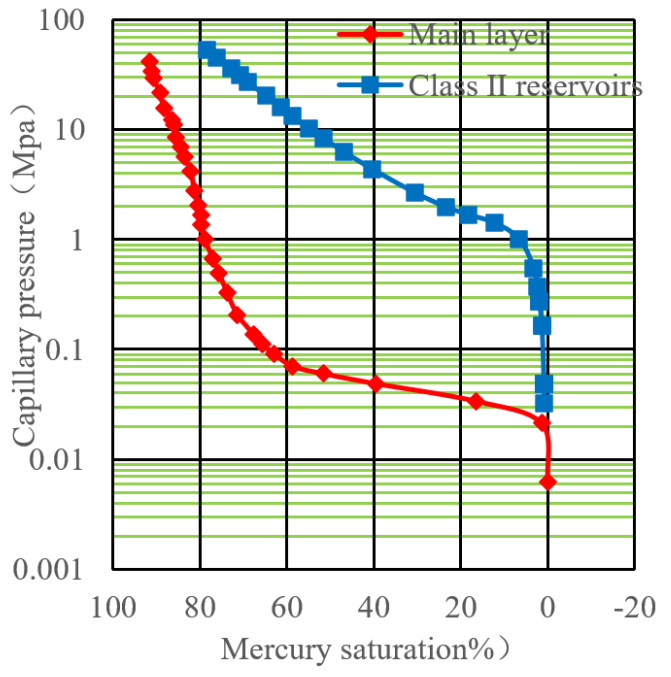

(a) The well 1

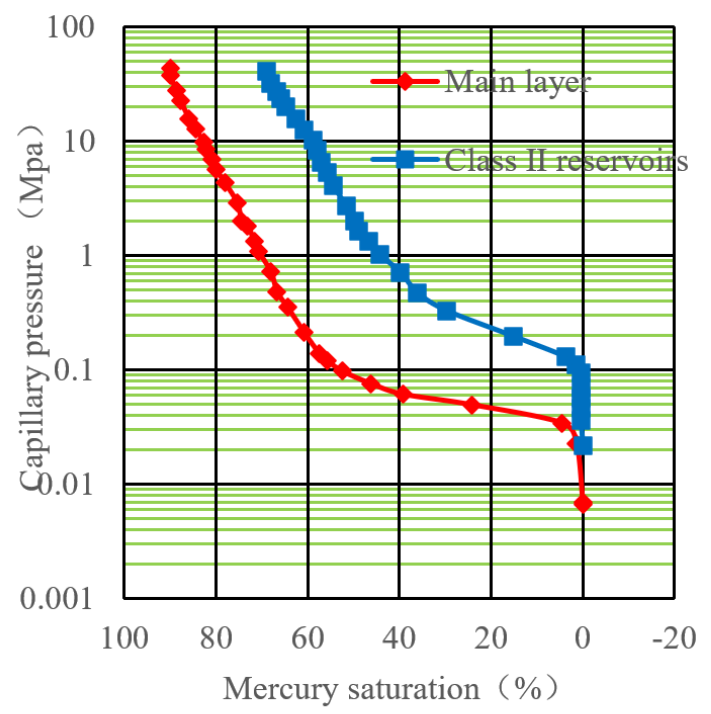

(b) The well 2

Figure 1. Capillary pressure curves of main and secondary reservoirs

\subsection{Comparative analysis of pore structure parameters and permeability}

The parameters describing pore structure characteristics can be divided into three categories: pore radius characteristic parameters, pore throat distribution characteristic parameters and pore throat connectivity characteristic parameters. Representative parameters are selected to evaluate the pore structure characteristics of the main and second-class oil reservoirs[6]. Table 1 shows the range of pore structure parameters of the main and second-class oil reservoirs.
Table 1. Pore structure parameters of main and secondary oil reservoirs

\begin{tabular}{|c|c|c|c|}
\hline Category & $\begin{array}{c}\text { Characteristic } \\
\text { parameters of pore } \\
\text { structure }\end{array}$ & $\begin{array}{l}\text { Major } \\
\text { reservoir }\end{array}$ & $\begin{array}{l}\text { The second } \\
\text { class } \\
\text { reservoir }\end{array}$ \\
\hline \multirow{3}{*}{$\begin{array}{l}\text { Pore radius } \\
\text { characteristic } \\
\text { parameters }\end{array}$} & $\begin{array}{c}\text { Maximum pore } \\
\operatorname{radius}(\mu \mathrm{m})\end{array}$ & $11.70 \sim 20.90$ & $6.25 \sim 17.60$ \\
\hline & $\begin{array}{l}\text { Mean pore } \\
\text { radius }(\mu \mathrm{m})\end{array}$ & $5.24 \sim 12.50$ & $2.21 \sim 9.03$ \\
\hline & $\begin{array}{l}\text { Median pore } \\
\text { radius }(\mu \mathrm{m})\end{array}$ & $2.90 \sim 16.60$ & $0.15 \sim 9.34$ \\
\hline \multirow{4}{*}{$\begin{array}{c}\text { Pore throat } \\
\text { distribution } \\
\text { characteristic } \\
\text { parameters }\end{array}$} & Sorting coefficient & $1.14 \sim 3.08$ & $2.70 \sim 4.77$ \\
\hline & $\begin{array}{c}\text { The mean } \\
\text { radius }(\mu \mathrm{m})\end{array}$ & $4.40 \sim 13.33$ & $1.34 \sim 8.73$ \\
\hline & $\begin{array}{l}\text { Relative sorting } \\
\text { coefficient }\end{array}$ & $0.14 \sim 0.88$ & $0.41 \sim 3.048$ \\
\hline & $\begin{array}{c}\text { Homogeneous } \\
\text { coefficient }\end{array}$ & $0.35 \sim 0.61$ & $0.23 \sim 0.51$ \\
\hline \multirow{4}{*}{$\begin{array}{l}\text { Pore throat } \\
\text { connectivity } \\
\text { characteristic } \\
\text { parameters }\end{array}$} & $\begin{array}{c}\text { Expulsion } \\
\text { pressure(MPa) }\end{array}$ & $0.02 \sim 0.06$ & $0.035 \sim 0.118$ \\
\hline & $\begin{array}{l}\text { Maximum } \\
\text { mercury intake } \\
\text { saturation(\%) }\end{array}$ & 83.59 99.20 & 64.60 98.01 \\
\hline & $\begin{array}{l}\text { The median } \\
\text { pressure(MPa) }\end{array}$ & $0.04 \sim 0.27$ & $0.076 \sim 5.148$ \\
\hline & $\begin{array}{c}\text { Characteristic } \\
\text { structural } \\
\text { parameter }\end{array}$ & $0.35 \sim 6.59$ & $0.117 \sim 0.961$ \\
\hline
\end{tabular}

(1) Mean pore radius

It can be seen from Table 1 that the average pore radius of class II oil reservoir ranges from $2.21 \mu \mathrm{m}$ to $9.03 \mu \mathrm{m}$. The average pore radius of the main reservoir ranges from $5.24 \mu \mathrm{m}$ to $12.50 \mu \mathrm{m}$. Figure 2 shows the relationship between average pore radius and permeability of the main reservoir and the secondary reservoir. It can be seen that the average pore radius of the main reservoir is $12.50 \mu \mathrm{m}$, while the average pore radius of the second type reservoir is $9.03 \mu \mathrm{m}$, so it can be seen that the main channel of the second type reservoir fluid flow is small[7]. There is a strong regularity between the average pore radius and permeability. With the increase of permeability, the average pore radius of the reservoir increases, and the average pore radius of the main oil layer is larger than that of the second oil layer, so the seepage channel of the main oil layer is larger than that of the second oil layer.

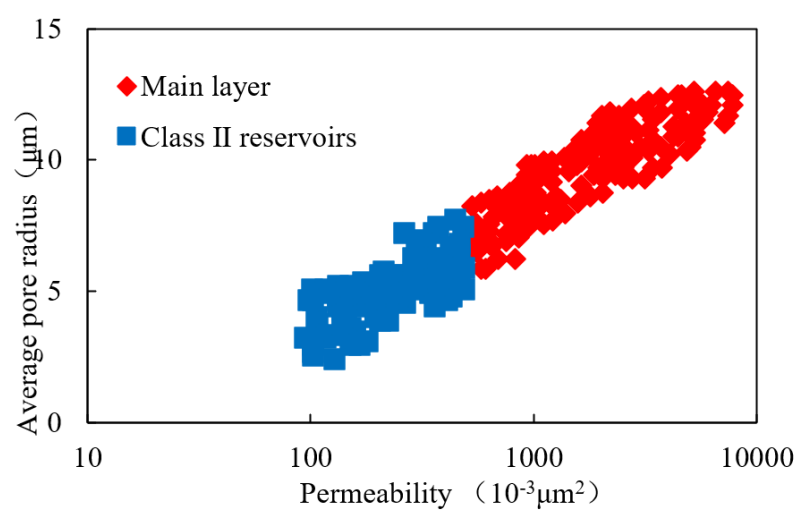

Figure 2. Relationship between average pore radius and permeability

(2) Sorting coefficient

The sorting coefficient is used to describe the distribution and concentration degree of pore-throat. The smaller the value is, the more uniform the pore-throat distribution is. Otherwise, the pore-throat distribution is worse. It can be 
seen from Table 1 that the sorting coefficient of the main oil reservoir ranges from 1.14 to 3.08 , and that of the second oil reservoir ranges from 2.70 to 4.77 . It can be seen that the pore throat distribution of the main oil reservoir is uniform, while the sorting of the second oil reservoir is relatively poor.

(3) Saturation median pressure

The size of median saturation pressure can indicate the size of oil and gas productivity. The higher the median saturation pressure is, the denser the reservoir rock is and the worse the permeability is. The lower the median saturation pressure is, the better the percolation ability of fluid in the reservoir is, and the higher the productivity is. For the main oil reservoir, the median saturation pressure ranges from $0.04 \mathrm{MPa}$ to $0.27 \mathrm{MPa}$, while for the secondary oil reservoir, the median saturation pressure ranges from $0.076 \mathrm{MPa}$ to $5.148 \mathrm{MPa}$. It can be seen that the secondary oil reservoir has poor seepage ability.

(4) Correlation between porosity and permeability

The permeability and porosity of 398 rock samples were statistically analyzed. Figure 3 shows the relationship curve between permeability and porosity of the main and secondary oil reservoirs. It can be seen that there is a strong correlation between porosity and permeability[8]. As the permeability increases, the porosity increases. The permeability of the second type oil layer is smaller than that of the main oil layer, and the porosity is small, indicating that the second type oil layer has poor reservoir physical properties.

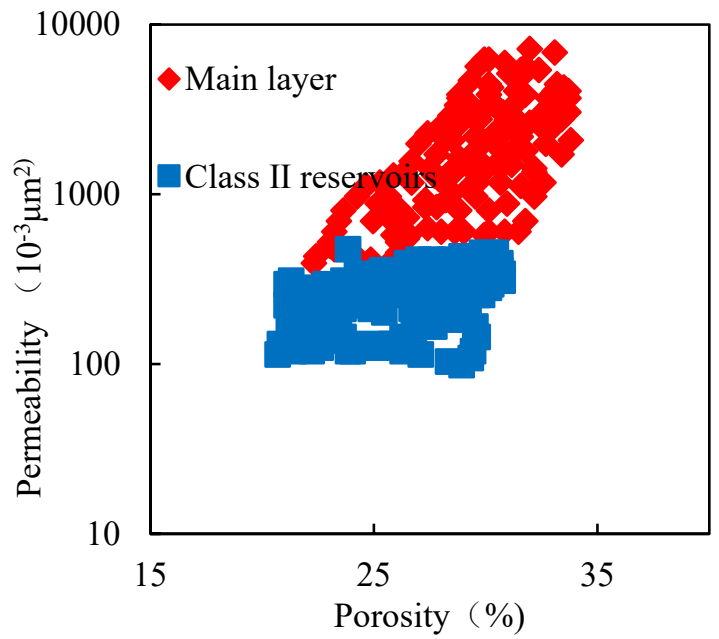

Figure 3. The relationship between permeability and porosity of main and secondary oil reservoirs

(5) Relationship between median pore radius and permeability

Figure 4 shows the relationship between the median pore radius and permeability of the main and secondary oil reservoirs. It can be seen that the median radius of the main oil reservoir is up to $15 \mu \mathrm{m}$, while the median radius of the secondary oil reservoir is only $5 \mu \mathrm{m}$. Therefore, the main channel of fluid flow in the second type oil reservoir is small. The regularity between the median radius and permeability is very strong. With the increase of permeability, the median pore radius increases and the permeability increases. There is a good correlation between the median pore radius and permeability, which is in the form of $\mathrm{Y}=\mathrm{AxB}$ with a high correlation coefficient above 0.9 .
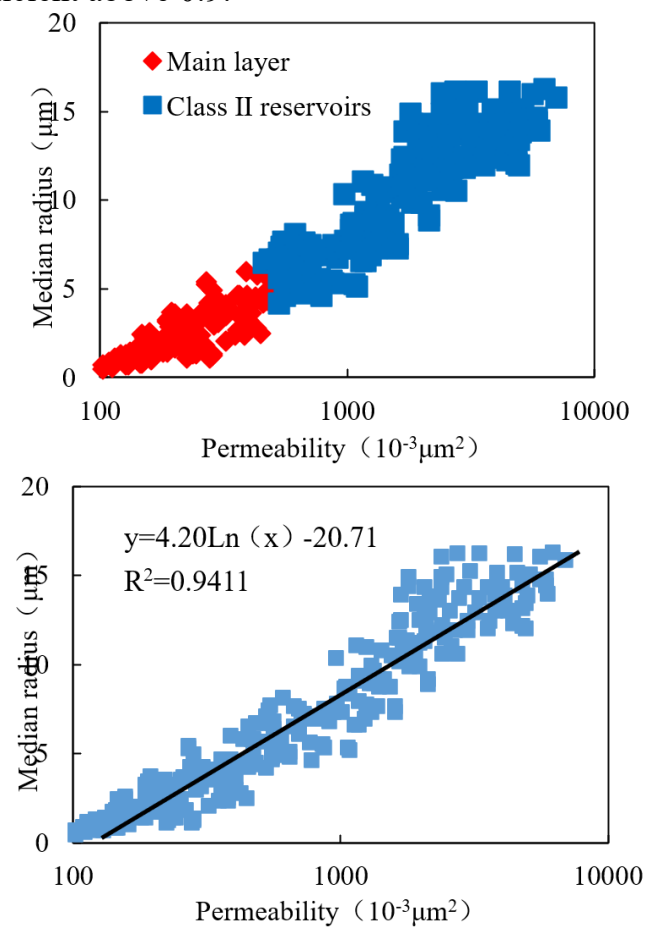

Figure 4. The relation curve between the median radius and permeability of the main reservoir and the secondary reservoir

(6) Relationship between drainage pressure and permeability

The relationship between permeability and displacement pressure in Figure 5 shows that high permeability and low displacement pressure of the main oil reservoir indicate good rock permeability. The larger the maximum pore radius is, the better the reservoir performance is. On the contrary, the second type reservoir has low permeability, and the higher the displacement pressure, the worse the reservoir performance.

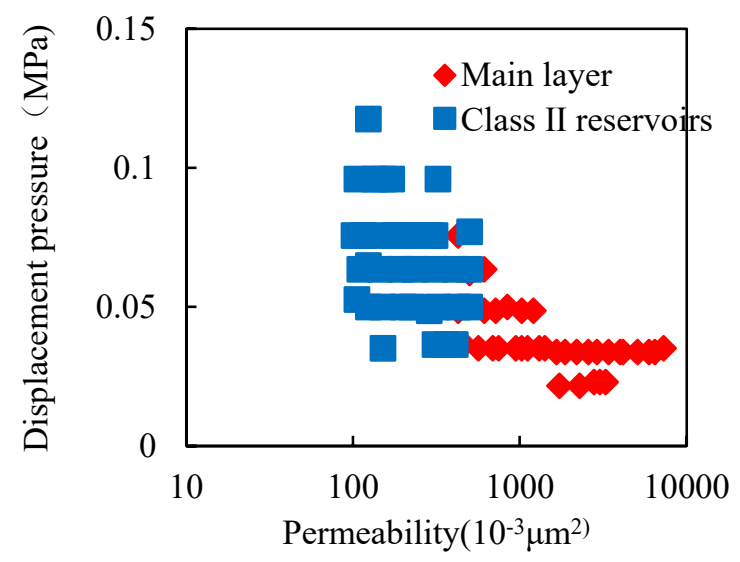

Figure 5. Relationship curve of displacement pressure and permeability between main and secondary oil reservoirs 


\section{Conclusion}

(1) According to the conventional mercury injection test data, the capillary pressure curve of the main oil reservoir is close to the lower left and has a gentle section, indicating that the main oil reservoir has high permeability, large pore radius, a large proportion of large pores, good pore-throat sorting, and low capillary pressure. The capillary pressure curve of the second type oil reservoir is far away from the horizontal axis. Compared with the main oil reservoir, the flat section is smaller, the permeability is lower, the pore-throat sorting is not good, and the displacement pressure is higher.

(2) The average pore radius of the main oil reservoir ranges from $5.24 \mu \mathrm{m}$ to $12.50 \mu \mathrm{m}$, and that of the second oil reservoir ranges from $2.21 \mu \mathrm{m}$ to $9.03 \mu \mathrm{m}$. The sorting coefficient of the main oil reservoir ranges from 1.14 to 3.08 , and that of the second oil reservoir ranges from 2.70 to 4.77. The pore throat distribution of the main oil reservoir is uniform, while the sorting coefficient of the second oil reservoir is relatively poor. The median saturation pressure of the main oil reservoir ranges from $0.04 \mathrm{MPa}$ to $0.27 \mathrm{MPa}$, while the median saturation pressure of the second oil reservoir ranges from $0.076 \mathrm{MPa}$ to $5.148 \mathrm{MPa}$. The second oil reservoir has poor seepage ability. The median radius of the main oil reservoir is up to $15 \mu \mathrm{m}$, while the median radius of the second oil reservoir is only $5 \mu \mathrm{m}$, and the correlation coefficient is higher than 0.9 . The main oil reservoir has high permeability, low displacement pressure and good rock permeability. The larger the maximum pore radius, the better the reservoir performance. On the contrary, the permeability of the second type reservoir is low, and the higher the displacement pressure is, the worse the reservoir performance is.

\section{References}

1. Wang Zheng.Study on classification of medium and low porosity and permeability reservoirs based on fractal characteristics [J] Marine geological frontier, 2021,37 (11): 78-84.

2. Liao Hai Water characteristic curve model of salinized soil based on pore structure [D] Northwest University of agriculture and forestry science and technology, 2021.

3. Xie Mingying, Dai Zong, Luo Donghong, Li Hailong, Tang Fang, Tu Zhiyong, Zhu Jian, Wang Chenchen A new method for residual oil characteristic analysis of heavy oil reservoir based on micron CT scanning displacement experiment [J] Unconventional oil and gas, 2020,7 (05): 102-107.

4. Shan Changan, Zhang Tingshan, Liang Xing, Hu Ranran, Zhao Weiwei Nano pore structure characteristics of high rank coals of vitrinite rich and inertinite rich formations [J] Journal of petroleum, 2020,41 (06): 723-736.

5. Song xinglei Study on the control mechanism of micro pore structure of tight sandstone reservoir on tight oil occurrence [D] Xi'an University of petroleum, 2020.

6. Pei zhansong, Zhu Yan Influence of diagenesis on different micro pore structure characteristics in Sazhong Development Zone [C] Proceedings of 2019 International Conference on oil and gas field exploration and development, 2019:2204-2209.

7. Zhu Haihua, Zhang Tingshan, Zhong Dakang, Li yaoyu, Zhang Jingxuan, Chen Xiaohui Binary pore structure characteristics of tight sandstone reservoir [J] Petroleum exploration and development, 2019,46 (06): 1220-1228.

8. Han Jin, Sun Wei, Bai yunyun, Zhang Qian, fan Xiujiang Study on fluid seepage characteristics and influencing factors of oil displacement efficiency of low permeability reservoir based on real sandstone micro water displacement experiment: taking Chang 6 reservoir of wangpanshan in Jiyuan oilfield as an example [J] Geological science and technology information, 2018,37 (06): 89-95. 